\title{
Portrait of Motor Learning for Kindergarten Students
}

\author{
Nuridin Widya Pranoto*, Mulyana Mulyana, Nurlan Kusmaedi \\ Sport Education Program \\ Faculty of Sport Education and Health \\ Universitas Pendidikan Indonesia \\ Setiabudhi Street No. 229, Bandung City, West Java, Indonesia \\ *tone_to@yahoo.co.id
}

\begin{abstract}
This study aims to get an overview of motor learning in kindergarten students. This research is descriptive type with a qualitative approach. Techniques used are interviews, observation, and documentation. The study sample consisted of 30 kindergarten teachers and 50 kindergarten students. Based on the results of the study obtained information that the process of motor learning is carried out well because the teacher has understood the purpose of motor learning and the formed of a system that controls the process, planning and evaluation of learning. The obstacle experienced by teachers is the lack of practical and integrated models of motor learning with other learning that attracts students. This obstacle is caused by the few integrated, practical, and interesting motor learning models that can be used by teachers in learning.
\end{abstract}

Keywords—kindergarten; motor; potret

\section{INTRODUCTION}

Early childhood education programs are a program aimed at children from birth to age 6 years [1], Early Childhood Education is a program carried out by the community to influence the development of children from infants to enter the consistent formal academic period [2]. Through the PAUD program children will be taught to know the world, interact, shape character, and have a tolerance attitude so that children are ready to pursue higher education. Some studies reveal that behavioral skills possessed by children will affect school readiness, success and early academic activities at school, [36]. Preschool education is a precondition for living real life, [7]. Preschool learning affects long-term success such as high school graduation, campus attendance, and annual income, [8].

Four competencies to be achieved by kindergarten students (4-6 years) are spiritual, social, knowledge, skill [9]. Physical education and school sports contribute to the domain: physical, social, affective and cognitive [10]. Motor skills are important for children because cognitive learning begins with movement sensitivity [11]. Abusive motor skills affect children in engaging play and a healthy lifestyle $[12,13]$. Lack of mobility has a negative impact, namely low self-confidence in physical activity, decreased life performance and increased obesity. In motion learning Children with low motor skills tend to be passive (audience), do not want to join in the game and tend to be solitary-functional play [14].

Some studies suggest that free play has not been able to promote the development of gross motor skills of children
$[15,16]$. The delay in motor skills is still experienced by children who play games freely even within 30 minutes [17]. The success of preschoolers in conducting sports activities is influenced by the role of the teacher in learning [18]. Experience in motor skills can be successful if there are careful plans in the learning program [19]. The many benefits of motor learning for kindergarten students are in stark contrast to the lack of literature describing motor learning activities. Based on these problems, it is necessary to have a clearer literature describing the potential of motor learning in kindergarten students. The purpose of this research is to get a portrait of motor learning in kindergarten which contains the teacher's understanding of the benefits of motor learning, the condition of infrastructure, the implementation of motor learning, security in learning, the obstacles experienced in the process of motor learning in kindergarten. and correlation of motor learning with academic ability.

\section{METHOD}

This research is descriptive type with a qualitative approach. The sample in this study consisted of 30 kindergarten teachers and 50 grade B kindergarten students aged 5-6 years from 10 kindergarten schools in Bandar Lampung. There are three steps taken, namely pre-field, data collection, and analysis. The pre-field stages are conducted by determining the kindergarten that will be used as the research sample, conducting research licensing, and validating the research instrument. Data collection techniques used are semistructured interview techniques, observation, and documentation. There are 20 questions for the teacher and 10 questions for students who have previously been validated by experts. Question items in the interview are designed to get a portrait of motor learning in kindergarten. The theme of interviews with teachers relates to the learning process, safety factors in learning, learning goals, learning strategies, learning infrastructure and constraints on motor learning. The theme of interviews with students is related to student interest, difficulties in learning, and basic academic questions that aim to see whether there are differences in methods of motor learning with cognitive abilities. Observations were made by adjusting the device of motor learning, learning infrastructure, students' reactions in the learning process with the results of interviews and physical evidence in the field. Documentation is done by taking photos and videos when research is then used to analyze and correlate the results of interviews, documents with 
reality in the field. The end of the research findings is then purified to reveal the learning process, the model of motor learning applied in kindergarten, the constraints faced, students' interests, and the impact of the model of motor learning on kindergarten students.

\section{RESULTS}

Based on the results of the comparison of the results of interviews, observations, and documentation obtained the following data (1) 25 or $83.3 \%$ of teachers carry out the learning process well, it can be seen from the readiness of teaching tools, the suitability of the teaching process with teaching materials, and evaluation at the end of learning . 5 or $16.6 \%$ of teachers have not carried out the learning process well as seen from incomplete teaching tools, differences in learning process with teaching materials, absence of learning evaluation. (2) It is known that 27 or $90 \%$ of teachers in the implementation of learning pay attention to safety factors by ensuring that learning infrastructure does not endanger students, and gives direction to students to be careful and supervise. 3 or $10 \%$ of teachers pay little attention to the security factor seen from the lack of supervision in the learning process. (3) It is known that 21 or $70 \%$ of teachers understand the purpose of motor learning in kindergarten, revealed from the results of interviews where the teacher can explain the benefits of movement for the child's body, the benefits of the child's social movements, the benefits of children's cognitive movement. 9 or $30 \%$ of teachers do not understand the purpose of motorized learning reflected at the time of the interview the teacher only knows motor learning only for physical fitness. (4) It is known that 24 or $80 \%$ of teachers who use the fun games learning model, and 6 or $20 \%$ of teachers use integrated fun games learning models. The difference in the learning model can be seen from the learning process carried out by the teacher in which 24 teachers carry out learning by playing and 6 teachers carry out learning through play which is integrated with basic mathematics and language learning such as counting, getting to know space, and knowing the alphabet. (5) It is known that 6 out of 10 kindergarten schools have adequate infrastructure for the learning process, as seen from the outdoor and indoor fields provided, outdoor game equipment and indoor game equipment. 4 schools lack adequate infrastructure as seen from the open space playing narrow spaces, the medium of outdoor and indoor playing games. (6) It is known that 9 or $30 \%$ do not experience problems in learning seen from the readiness of the learning program, the making of modification of teaching materials, and the smooth running of the learning process. 21 or $70 \%$ of teachers experience obstacles in the process of motor learning, the biggest obstacle is the lack of models of motor learning that can be used as learning guides.

Based on the comparative research findings from the results of interviews, observations, and documentation on students it is known (1) 40 or $80 \%$ of students like motoric lessons conducted in kindergarten, seen from the enthusiasm of students before carrying out learning and when implementing learning and after implementing learning. 10 or $20 \%$ of students are less antisisic in learning seen from the lack of enthusiasm, some students just sit watching learning. (2) It is known that 32 or $64 \%$ of students do not experience motor learning difficulties seen from the active and agile students doing the motion instructed by the teacher. 18 or $36 \%$ of students who experience difficulties in the process of motor learning, seen when implementing learning students move stiffly and difficult to follow the movements instructed by the teacher. (3) It is known that 20 or $40 \%$ of students who can answer basic math questions correctly are seen during the interview of 20 children who answered the questions correctly. 30 or $60 \%$ of students have not answered the question correctly seen in the interview the child incorrectly answered the question given.

\section{DISCUSSION}

Some research results that need to be discussed include, the application of a system such as a teaching team, meeting on the determination of teaching materials and an internal supervisory system and external supervisors making the learning process more programmable and well implemented. Kindergarten teacher awareness of the security factor in the implementation of learning must be accompanied by standardized infrastructure facilities. High awareness but not supported by safe infrastructure can cause injury to students while carrying out learning. The need for continuous programmed socialization so that the objectives of motor learning in the cognitive aspects of affective and psychomotor are known and understood by the teacher. The participation of preschoolers in sports is beneficial for cognitive, physical, social and emotional development, [20]. Increased understanding of the purpose and impact of motor learning will stimulate teachers to do motor learning correctly.

In this study it is known that there are two learning models applied, the first is the fun game model and the second is the integer fun game model. The two models have in common, namely learning through fun playing activities that lead to the child's making a move so that he gets physical health. The difference lies in integer games fan learning where in the motoric learning process the teacher includes basic math materials such as mentioning numbers on students jumping, running to compile the number of numbers that have been determined, and introducing the type of flat build to students. Although at the learning stage of kindergarten students the counting material is not compulsory but through an integrated learning process of learning it is expected to stimulate students to like other lessons such as basic mathematics. Currently education in early childhood institutions does not only focus on preparing children for school, but for everyday life in general [7]. The implementation of learning must be adjusted to the stages of child motor development [21]. Further research is needed to find out whether there is an effect of fun learning model on integer games with the interest in learning to count and basic math skills of students.

Facilities and infrastructure are needed supporting learning factors. The findings of field infrastructure research are still dominated by the field of paving blocks so that the level of security is still relatively low. The infrastructure in learning that uses fun games integration models is still minimal and the equipment is still in the form of a prototype. There needs to be further research regarding the standard of infrastructure 
facilities in kindergarten and the creation of integration fun game learning media. The lack of peractic and interesting models of motor learning is a constraint for teachers when implementing learning. The existing model feels a lot of time for learning preparation, requires large space, uses large equipment, and the learning model patterns are individual so it does not encourage students to cooperate and the implementation of the model takes a long time so students sometimes feel bored while waiting their turn. In applying the learning model, the teacher must be able to choose and adjust to the character of students. An intervention in motor learning is not necessarily suitable for all children [22].

Portrait of motor learning seen from a student's perspective. There are several kindergarten students who express boredom about the material being taught. Boredom arises because the repetition of material that is less attractive and students are too long waiting to play. Some students experience difficulties in the learning process, average movement difficulties experienced by obese and shy students. Boredom and difficulty of movement caused by obesity have the potential to make students not confident. There must be special handling for children who experience difficulties in motor learning. Motor skills are the result of subsystem interactions between students, environment and tasks [23]. Each student experiences different motor development to obtain the same results [24]. Students who are in the process of motor learning using the integer fun game method look confident in answering basic math questions and can answer the questions correctly.

\section{CONCLUSION}

The lack of models of motor learning that are integrated with other learning needs to be addressed with the creation of learning models according to the stages of development and character of children. There needs to be standardization of facilities and infrastructure in kindergartens because the existence of infrastructure has affected the safety and interest of students to move. The high interest of kindergarten students to carry out motor learning needs to be supported by good learning programs. Obstacles experienced by students in motor learning are dominated by internal factors of students. Motor learning with integer models improves students' basic math skills.

\section{REFERENCES}

[1] D. P. A. U. Dini, Kurikulum Pendidikan Anak Usia Dini, Jakarta, 2015

[2] R. M. Thomas, "Universal and culturally specific criteria for evaluating early-childhood-education programs", Early Child Development and Care, 26:1-2, 105-122, 1986.

[3] R. Bulotsky-Shearer, J. W. Fantuzzo, and P. A. McDermott, “An investigation of classroom situational dimen-sions of emotional and behavioral adjustment and cognitive and social outcomes for Head Start children," Developmental Psychology, 44, 139-154, 2008.

[4] S. E. Rimm-Kaufman, R. C. Pianta, and M. J. Cox, "Teachers' judgments of problems in the transition to kindergarten," Early Childhood Research Quarterly, 15, 147-166, 2000.

[5] C. Webster-Stratton and M. J. Reid, "The incredible years parents, teachers, and children training series: A multifaceted treatment approach for young children with conduct disorders," In J. R. Weisz \& A. E. Kazdin (Eds.), Evidence-based psychotherapies for children and adolescents (2nd ed., pp. 194-210). New York, NY: Guilford Press, 2010 .

[6] J. A. Welsh, R. L. Nix, C. Blair, K. L Bierman, and K. E. Nelson, "The development of cognitive skills and gains in academic school readiness for children from low-income families," Journal of Educational Psychology, 2010

[7] Õ. Tiia, S. U. Aino and N. Katrin, "The views of kindergarten staff on educational objectives in post-socialist society," Tallinn University, Estonia, 2008

[8] F. A. Campbell, C. T. Ramey, E. Pungello, J. Sparling, and S. MillerJohnson, "Early childhood education: Young adult outcomes from the Abecedarian project," Applied Developmental Science, 6, 42-57, 2002.

[9] D. P. A. U. Dini, Kerangka Dasar Dan Struktur Kurikulum 2013. Jakarta, 2015

[10] B. Richard, A. Kathleen, K. David, J. Mike, P. Ian, S. Rachel and BERA P. E. and S. P. S. I. Group, "The educational benefits claimed for physical education and school sport: an academic review," Research Papers in Education, 2010

[11] D. L. Gallahue and F. C. Donnelly, Developmental physical education for all children, Champaign, IL: Human Kinetics, 2003.

[12] Y. Bar-Haim and O. Bart, "Motor Function and Social Participation in Kindergarten Children." Social Development 15: 296-310, 2006

[13] K. E. Cohen, P. J. Morgan, R. C. Plotnikoff, R. Callister, and D. R. Lubans, "Physical Activity and Skills Intervention: SCORES Cluster Randomized Controlled Trial," Medicine and Science in Sports and Exercise 47 (4): 765-774, 2015

[14] A. Kennedy-Behr, S. Rodger, and S. Mickan, "Physical and Social Play of Preschool Children with and Without Coordination Difficulties: Preliminary Findings," The British Journal of Occupational Therapy 74: 348-354, 2011

[15] S. Iivonen and A. K. Saakslahti, "Preschool Children's Fundamenta Motor Skills: A Review of Significant Determinants," Early Child Development and Care 184 (7): 1107-1126, 2013.

[16] S. W. Logan, L. E. Robinson, A. E. Wilson and W. A. Lucas, "Getting the Fundamentals of Movement: A Metaanalysis of the Effectiveness of Motor Skill Interventions in Children." Child: Care, Health and Development 38 (3): 305-315, 2011.

[17] I. Hürmeriç-Altunsöz and J. D. Goodway, "SKIPing to Motor Competence: The Influence of Project Successful Kinesthetic Instruction for Preschoolers on Motor Competence of Disadvantaged Preschoolers," Physical Education and Sport Pedagogy, 2015

[18] P. Karen, Nonis, "Kindergarten teachers' views about the importance of preschoolers' participation in sports in Singapore," Early Child Development and Care, 175:7-8, 719-742, 2007.

[19] J. D. Goodway and C. F. Branta, "Influence of a Motor Skill Intervention on Fundamental Motor Skill Development of Disadvantaged Preschool Children," Research Quarterly for Exercise and Sport 74 (1): 36-46. 2003.

[20] C. Gabbard, "Outcome-based preschool physical education," International Journal of Physical Education, 37(1), 17-23, 2000.

[21] J. D. Goodway, R. Famelia and S. Bakhtiar, "Future directions in physical education \& sport: developing fundamental motor competence in the early years is paramount to lifelong physical activity," Asian Social Science, 10(5), 44, 2014

[22] S. Bakhtiar, "Fundamental motor skill among 6-year-old children in Padang, West Sumatera, Indonesia," Asian Social Science, 10(5), 155158, 2014.

[23] K. M. Newell, "Constraints on the development of coordination," In M G. Wade \& H. T. A. Whiting (Eds.), Motor development in children: Aspects of coordination and control (pp. 341-360). Dordrecht, The Netherlands: Nijhoff, 1986.

[24] S. Bakhtiar, "The implementation of dynamic system theory and the principles of growth in physical education of elementary school," Asian Social Science, 9(12), 105, 2013. 